\title{
Formação (crítica) de professores na EaD: um estudo com base no curso "Uso Educacional Da Internet"
}

\author{
Francieli Aparecida Dias Fagundes, Ana Carolina G. Inocêncio ${ }^{1}$, \\ Heitor A. X. Costa ${ }^{2}$, Paulo Afonso Parreira Júnior ${ }^{2}$ \\ ${ }^{1}$ Curso de Ciência da Computação - Universidade Federal de Jataí (UFJ) \\ 75.801-615 - Jataí - GO - Brasil \\ ${ }^{2}$ Departamento de Ciência da Computação - Universidade Federal de Lavras (UFLA) \\ Caixa Postal 3037 - 37.200-900 - Lavras - MG - Brasil \\ francielidias.heliodora@yahoo.com.br, anainocencio@ufj.edu.br, theitor, \\ pauloa.junior\}@ufla.br
}

\begin{abstract}
Considering the importance of teacher training in the context of significant transformations driven by new technologies, this work aims to identify and discuss possibilities of critical training of teachers in distance education, especially in the course "Uso Educacional da Internet". To do so, a bibliographic research is undertaken, the course design is analyzed, as well as some data collected in a discipline and others generated through questionnaires. From the study, it is concluded that it is very important that teacher training processes present different approaches and not fail to contemplate a critical-reflexive, so that classroom practices contribute to the training of subjects in a holistic sense.
\end{abstract}

Resumo. Tendo em vista a importância da formação docente em meio a significativas transformações impulsionadas pelas novas tecnologias, este trabalho objetiva identificar e discutir possibilidades de formação crítica de professores na educação a distância, de modo especial no curso "Uso Educacional da Internet”. Para tanto, empreende-se uma pesquisa bibliográfica, o projeto do curso é analisado, assim como alguns dados coletados em uma disciplina e outros gerados por meio de questionários. A partir do estudo, conclui-se que é de suma importância que processos de formação docente apresentem abordagens diversas e não deixem de contemplar um cunho crítico-reflexivo, para que as práticas em sala de aula contribuam para a formação dos sujeitos em um sentido holístico.

\section{Introdução}

Em tempos em que as novas tecnologias redesenham as práticas diárias dos indivíduos, é importante refletir sobre a sua influência na educação, uma vez que, de acordo com Pinheiro (2011), a escola parece ser uma das poucas instituições que ainda resistem a tantas transformações. Os discursos que circulam na sociedade evidenciam as diversas causas para essa resistência, entre elas [MORAN, 2009]: (i) as limitações dos espaços escolares no que tange aos recursos tecnológicos e o acesso à Internet; e (ii) a formação docente que, em muitos casos, não abarca questões atuais sobre as novas tecnologias e a educação. Assim, embora a apropriação das Tecnologias Digitais de Informação e 
Comunicação (TDIC) em sala de aula seja importante, muitas vezes, as realidades vivenciadas dificultam esse outro modo de agir e de ser.

Nesse contexto, é possível perceber cada vez mais esforços para que a discussão sobre novas tecnologias e educação ganhe espaço entre os envolvidos nas práticas escolares. Cursos de formação continuada podem ser vistos como um exemplo disso, uma vez que muitos professores, que mediam o processo de construção de conhecimento, não tiveram em sua formação inicial a oportunidade de discutir e refletir sobre as TDIC na educação. Contudo, é relevante considerar quais perspectivas de formação podem estar envolvidas nesses processos formativos, e se neles os professores se reconhecem como sujeitos capazes de estabelecer mudanças constantes e profundas em seus contextos e na sociedade como um todo [LIBERALLI, 2010].

Sendo assim, a motivação para esta pesquisa reside na importância de compreender em que medida eventos de formação continuada, como o curso "Uso Educacional da Internet" (UEI), dialogam com um processo de formação que vai além do tradicional ${ }^{1}$, mas que seja dialético, reflexivo, crítico, investigativo, organizado a partir de contextos educativos e das necessidades dos sujeitos a quem se destina [KRAHE, 2006]. Enfim, se a docência (ainda) é concebida como de suma importância no processo de construção de conhecimento e na formação dos sujeitos para a vida em sociedade, é justificável, e premente, que ela continue sendo escopo de pesquisas.

Dados recentes apresentados pela Associação Brasileira de Educação a Distância (ABED) mostram que o número de cursos oferecidos cresce consideravelmente, assim como o número de pessoas que buscam oportunidades na EaD (Educação a Distância). Em um de seus relatórios (2017, p. 7), afirma-se que a EaD o acesso à formação continuada em todos os níveis profissionais, complementando a formação acadêmica formal. Contudo, o documento deixa claro que cursos de aperfeiçoamento e extensão tendem a atrair alunos em busca de crescimento profissional.

Frente a essa realidade, a questão de pesquisa que motiva a realização deste trabalho é: a formação continuada de professores em cursos a distância tem possibilitado vivências significativas que possam contribuir para o ser e o agir docente em uma perspectiva crítica?

Assim, com o intuito de responder a essa questão, algumas questões secundárias foram propostas, considerando como estudo de caso um curso a distância oferecido pela Universidade Federal de Lavras (UFLA), denominado "Uso Educacional da Internet $(\mathrm{UEI})^{2}$ ":

\footnotetext{
${ }^{1}$ É importante esclarecer que o presente trabalho não pretende criticar a abordagem tida como tradicional na educação, pelo contrário, o que se defende aqui é um equilíbrio entre ela e uma abordagem mais crítica e reflexiva, uma vez que se reconhece que pode haver aspectos positivos em cada uma das abordagens até hoje nomeadas por estudiosos da área da educação. Em outros momentos neste trabalho, essa questão será retomada.

${ }^{2} \mathrm{O}$ curso foi criado frente à necessidade de formação de professores para utilizar os recursos interativos da internet, especialmente aqueles ligados à web 2.0, como ferramenta de apoio ao processo de construção de conhecimento. Outras informações sobre o curso são apresentadas neste trabalho posteriormente na Seção 3.
} 
1. Quais perspectivas de formação docente estão envolvidas nas atividades realizadas pelos professores no curso?

2. Há possibilidades, considerando o projeto do curso e a forma como as atividades são desenvolvidas, de uma formação crítica-reflexiva, haja vista a sua pertinência em meio às constantes transformações sociais contemporâneas?

3. Os professores se engajam em suas vivências formativas ou é notório o anseio pelo crescimento profissional apenas?

Para isso, em um primeiro momento, foi empreendida uma pesquisa bibliográfica, com vistas à apropriação de conceitos basilares e à compreensão do contexto de transformações em que se insere este estudo (Seção 2). Além da pesquisa bibliográfica, dados foram coletados no curso UEI. A fim de não ultrapassar os limites de espaço estabelecidos para este artigo, mas considerando as possibilidades de discussão das questões colocadas na introdução, as atividades de 1 (uma) disciplina do curso, a saber "Uso Educacional dos Recursos Interativos da Web", foram analisadas ${ }^{3}$.

Ademais, o projeto pedagógico do curso foi também, mesmo que brevemente, analisado com vistas a identificar a(s) sua(s) perspectiva(s) de formação docente. Por fim, dados foram gerados por meio de questionários respondidos por professores-cursistas, contendo algumas questões para caracterização de perfil dos participantes e outras relacionadas à discussão que se pretende empreender nesta pesquisa (Seção 3).

\section{Discussão Teórica}

A educação na contemporaneidade, assim como em outras épocas de nossa história, tem sido repensada frente às mudanças vivenciadas na sociedade. A emergência e a disseminação de novas tecnologias têm redefinido as práticas cotidianas e feito provocações no sentido de refletir sobre uma educação que congregue as tecnologias que há muito tempo têm lugar na escola com aquelas consideradas novas.

$\mathrm{Na}$ versão mais recente da Base Nacional Comum Curricular, é possível perceber as TDIC perpassando a Educação Infantil, o Ensino Fundamental e o Ensino Médio, bem como as competências no interior de cada uma dessas etapas. Consta, no documento, que uma das competências gerais da Educação Básica é:

Compreender, utilizar e criar tecnologias digitais de informação e comunicação de forma crítica, significativa, reflexiva e ética nas diversas práticas sociais (incluindo as escolares) para se comunicar, acessar e disseminar informações, produzir conhecimentos, resolver problemas e exercer protagonismo e autoria na vida pessoal e coletiva. (BRASIL, 2018, p. 9).

Contudo, é importante que tenha-se ciência de que para compreender, utilizar e criar TDIC com criticidade, é importante que essas novas tecnologias sejam apropriadas na escola como recursos e como discursos no processo de construção de conhecimento, o que, infelizmente, ainda não ocorre em muitos contextos escolares por algumas razões. Neste trabalho, será discutida a (não)formação docente como uma dessas razões,

\footnotetext{
${ }^{3}$ A respeito da disciplina, é válido esclarecer que ela foi escolhida, uma vez que apresentou um maior número de fóruns, bem como de participações em cada um deles.
} 
uma vez que os professores, como mediadores, são atores fundamentais nas transformações e nas estabilidades em salas de aula.

A respeito do processo de formação docente, apesar de já serem evidentes as mudanças nas grades curriculares em cursos de formação inicial em licenciaturas, é preciso considerar que há um número considerável de professores que passou pelo seu primeiro curso há anos, e que, por isso, não tiveram a oportunidade de vivenciar discussões que abarcavam questões relacionadas às novas tecnologias na escola. Nesse cenário, cursos de formação continuada, principalmente os oferecidos na modalidade a distância, parecem estar suprindo carências formativas, como mostra o relatório analítico da aprendizagem a distância no Brasil referente ao ano de 2016.

É importante, todavia, refletir sobre essas experiências de formação e suas perspectivas, afinal, ao participar de um curso, como o de "Uso Educacional da Internet", existe a busca de progressão na carreira profissional ou de uma formação que ajude a transformar realidades? Existe a busca apenas do "como fazer/ser" ou também do "por que fazer/ser"?

De acordo com Krahe (2006), as concepções de formação de professores podem ser reunidas em duas grandes tendências. A primeira é identificada como estruturante, uma vez que está relacionada à formação tradicional, comportamentalista, tecnicista, que define previamente programas, procedimentos e recursos a partir de uma lógica de racionalidade técnica e instrumental sem a consideração de diversidade de contextos e de sujeitos. A segunda, concebida como interativo-construtivista, é dialética, reflexiva, crítica e investigativa, organizada a partir de contextos educativos e das necessidades dos sujeitos a quem se destina. Desse modo, a primeira pode ser associada ao que se tem discutido como educação neoliberal e a segunda como educação crítica.

Para compreender o que se tem chamado de educação neoliberal, é importante considerar, conforme afirma Ianni (1996), que o neoliberalismo articula prática e ideologicamente os interesses dos grupos, classes e blocos de poder organizados em âmbito mundial. Segundo Prates (1995), nessa lógica, o homem é reconhecido como objeto e não como sujeito, já que a centralidade fica na técnica e no capital; a sociedade é identificada como espaço recriador da exclusão; os processos sociais são construídos por interesse da "minoria". Nesse contexto macro, a educação, vista como estratégica a qualquer projeto de poder, também passa a funcionar de acordo com esses mecanismos a fim de servir aos ideais dessa configuração social [NETO e CAMPOS, 2017, p. 10991].

No que concerne à educação crítica, com base em Paulo Freire, pode-se dizer que ela é orientada para a tomada de decisões e o exercício da prática com uma responsabilidade social e política. Nesse contexto,

$\mathrm{O}$ educando precisa assumir-se como tal, mas assumir-se como educando significa reconhecer-se como sujeito que é capaz de conhecer o que quer conhecer em relação com o outro sujeito igualmente capaz de conhecer, o educador e, entre os dois, possibilitando a tarefa de ambos, o objeto de conhecimento. Ensinar e aprender são assim momentos de um processo maior - o de conhecer, que implica re-conhecer. (2003, p. 47) 
Diante disso, é indiscutível a importância da relação que se estabelece entre professores e estudantes no decorrer do processo de construção de conhecimento e de constituição identitária, o que justifica o fato de que a formação docente deve ser constantemente (re)pensada.

Segundo Liberalli (2010), o trabalho com educadores, pensando no processo de formação crítica, atua no sentido de: transferir as suas formas de agir a outros contextos; criar a possibilidade de transformação de conceitos, práticas, modos de participação e ação conjunta (p. 22); e desenvolver um trabalho que se volte para a formação de cidadãos mais críticos. A autora considera a importância da reflexão no processo de formação docente, e amplia a sua discussão nesse sentido apresentando, com base em Van Manen (1997), a reflexão técnica, a reflexão prática e a reflexão crítica, que, nesta pesquisa, nos ajudarão a olhar para os dados buscando traços de uma formação crítica.

É importante ressaltar que a visão de educação que vigora neste trabalho embasa-se em autores como Moita Lopes (1996), que concebe a educação como um processo essencialmente cultural e social, em que professores e estudantes constroem conhecimentos de forma conjunta. Tem como base também autores como Paulo Freire, que reconhece a educação como um ato político e ideológico, o que elucida a importância que cada vez mais tem se dado a um processo crítico de formação docente.

\section{Discussão e Análise dos Dados}

Como já exposto, para a consecução da proposta deste trabalho, a pesquisa tem lugar no curso UEI. Então, sobre esse contexto, é importante mencionar que se trata de um curso de pós-graduação latu sensu, com duração de três períodos (dezoito meses). É oferecido na modalidade a distância por meio do sistema da Universidade Aberta do Brasil (UAB). O curso é composto por onze disciplinas, as quais propuseram diversos tipos de atividades realizadas pelos professores-cursistas para fins de avaliação, tais como fórum de discussão, envio de tarefas, glossário, diário, entre outros. Ao todo, os professores cursistas devem cumprir 420 horas de atividades.

No caso deste trabalho, a disciplina eleita para análise foi "Uso Educacional dos Recursos Interativos da Web", uma vez que além dos envios de tarefa, das anotações que deveriam ser feitas no diário e da escrita colaborativa, apresentou quatro fóruns de discussão. O volume de postagens foi, portanto, consideravelmente maior, com indagações teóricas e práticas, sempre relacionadas, que pareciam instigar professores-cursistas e fazê-los refletir sobre questões de suma importância relacionadas ao uso educacional da Internet. Ademais, essa foi a única disciplina citada nas respostas recebidas a partir do questionário por meio do qual dados foram gerados para esta pesquisa.

Retomando o objetivo deste trabalho, identificar e discutir possibilidades de formação crítica de professores na educação a distância, de modo especial, no curso "Uso Educacional da Internet", em um primeiro momento, antes mesmo de realizar uma análise a partir da disciplina supracitada, acredita-se na importância de considerar o Projeto Pedagógico do Curso (PPC), com vistas a identificar a(s) sua(s) perspectiva(s) de formação docente, para, assim, refletir sobre as possibilidades de uma formação crítica. 
No PPC, após os dados de identificação, são apresentadas as informações a respeito da concepção e ideário pedagógico. De acordo com o documento, no que concerne aos princípios formadores do curso, ele foi criado a partir da necessidade de preparar profissionais para utilizar os recursos interativos da internet, especialmente aqueles ligados à web 2.0, como ferramenta de apoio ao processo de ensino-aprendizagem. No PPC, fica clara a preocupação em relacionar constantemente teoria e prática, como se pode observar por meio do trecho a seguir:

O curso foi planejado de forma a entremear atividades práticas e teóricas, dando subsídios concretos ao cursista para uma avaliação mais profícua das possibilidades educacionais da internet. [...] O Objetivo principal do curso é formar professores e profissionais da educação para fomentar a criação e realização de projetos educacionais utilizando os recursos da Web 2.0 e tendo em conta as características locais e regionais e as especificidades dos educandos, instrumentalizando-os para o uso das tecnologias da Internet em prol da educação.

A respeito da concepção pedagógica, no PPC lê-se que o curso procura ser um espaço que propicia discussão sobre a importância da tecnologia educacional e instrumentaliza professores para fazer um bom uso dos recursos da web, a fim de trazer melhorias ao processo de ensino-aprendizagem. A partir dessas considerações, é possível perceber alguns pontos que indiciam a possibilidade de uma perspectiva de formação mais crítica e reflexiva, uma vez que se mantem a ideia de instrumentalizar, que está relacionada à uma abordagem mais tecnicista, que, é importante lembrar, não deixa de ter um papel relevante em processos formativos.

Como justificativa de criação, explicita-se que o curso foi criado como resposta às novas demandas da educação em meio às transformações na sociedade ocasionadas pelas TDIC. Assim, "é um curso de formação continuada de professores de educação básica com o objetivo de preparar e capacitar esses profissionais para selecionar, adequar, pesquisar e desenvolver recursos didáticos com uso das Tecnologias da Informação.". Sobre os objetivos do curso, consta no PPC que o principal é formar profissionais da educação para propor e implantar projetos educacionais utilizando os recursos da web 2.0, especialmente aqueles mais próximos da realidade dos estudantes. É válido retomar aqui, quando considera-se esse objetivo, o que escreve Liberalli (2010) sobre a importância de ser o processo de formação docente baseado na reflexão, que deve ser técnica, prática e crítica.

A partir de um olhar analítico em relação ao PPC do curso UEI, uma interpretação possível é de que, a depender da forma como o curso é conduzido, parece se manter as ideias de uma perspectiva mais tradicional de formação, havendo, contudo, abertura para situações reflexivas. Além do PPC, este trabalho apresenta também uma observação analítica da disciplina "Uso Educacional dos Recursos Interativos da Web", uma das que compõem o curso $\mathrm{UEI}^{4}$. A disciplina dispõe de 11 atividades avaliativas, entre elas quatro fóruns de discussão: o primeiro relacionado ao processo de formação de professores, o segundo à pesquisa na internet, o terceiro à privacidade em espaços da

\footnotetext{
${ }^{4}$ É importante esclarecer que indícios de uma formação crítica podem ser percebidos na maioria das disciplinas, todavia, como já sinalizado, tendo em vista os limites do presente trabalho, uma apenas foi eleita para análise, conforme o critério já apresentado.
} 
internet e o quarto à uma experiência de leitura e sistematização de ideias. Além dos fóruns, é importante considerar as propostas para a elaboração de textos que deveriam ser enviados como tarefas. Nessa disciplina, os professores-cursistas foram convidados a discutir/refletir sobre os papéis de estudantes e professores na contemporaneidade.

No primeiro fórum da disciplina, a orientação é de que os professores busquem artigos científicos que abordem questões relacionadas à formação de professores e práticas com novas tecnologias na escola. Cada professor-cursista deveria compartilhar sua leitura de uma maneira sistematizada e dar uma nota à postagem de um colega de curso pela sua contribuição no fórum e atendimento à proposta. Não se pode deixar de destacar a importância da tutoria no decorrer desse processo. As suas intervenções eram sempre pontuais e contextualizadas, de modo a direcionar provocações e, assim, incitar novas discussões. A Figura 1 mostra a postagem da tutora após as primeiras participações no fórum.

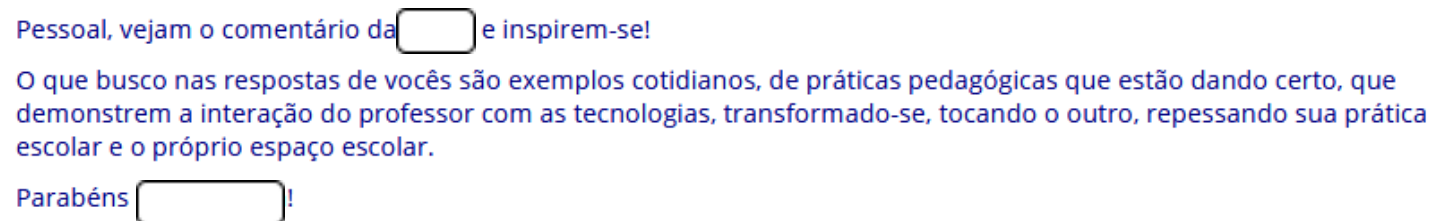

Figura 1: Comentário da tutora no fórum de discussão - interação 1.

No fórum seguinte, sobre privacidade, os professores-cursistas deveriam compartilhar notícias sobre o assunto, bem como contribuir para a construção de uma discussão sobre as questões emblemáticas que o envolvem. Após a participação inicial, a tutora, como mediadora, faz a seguinte postagem, conforme se verifica na Figura 2.

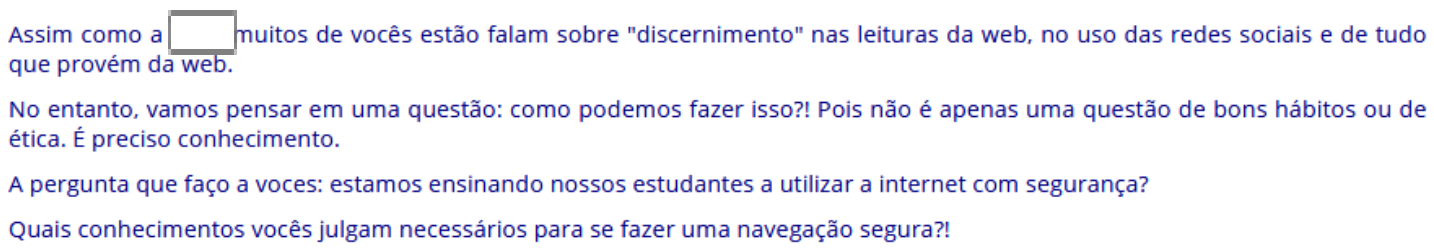

Figura 2: Comentário da tutora no fórum de discussão - interação 2.

A partir dessas figuras, é possível perceber de que forma essas discussões se deram e fazer uma relação com o que discute Liberalli (2010) sobre uma formação de professores que atua no sentido de transferir as suas formas de agir a outros contextos; criar a possibilidade de transformação de conceitos, práticas, modos de participação e ação conjunta, afinal, não basta reconhecer as potencialidades das novas tecnologias na educação, é necessário também estar ciente dos possíveis perigos e, principalmente, dos cuidados que devemos ter no meio "virtual". Apesar das queixas dos professores-cursistas sobre a falta de tempo, as inserções eram, na maioria das vezes pertinentes e relacionadas ao assunto em discussão.

Por fim, dados foram gerados por meio de questionários respondidos por professores-cursistas, contendo algumas questões para caracterização de perfil dos participantes (faixa etária e formação inicial) e outras relacionadas à discussão que se pretende empreender nesta pesquisa: 1) o que levou você a se inscrever para o curso 
"Uso Educacional da Internet”?; 2) a partir dos conhecimentos por você construídos no decorrer de seu processo formativo, o curso pode ser considerado: comportamentalista e tecnicista ou reflexivo e crítico?; 3) Justifique a sua resposta anterior.; 4) Escreva um breve relato sobre sua experiência até o momento no curso.

Os questionários foram elaborados por meio da ferramenta Google Forms e encaminhados aos professores-cursistas em um grupo de WhatsApp utilizado para comunicação entre os participantes de um dos pólos do curso. No questionário, os professores cursistas não se identificaram, mantendo o anonimato. No que diz respeito às questões, elas foram elaboradas de modo a não direcionarem respostas e considerando a possibilidade de discussão das questões propostas neste trabalho.

Entre os participantes da pesquisa, estão 3 (três) professores-cursistas com idade entre 30 e 40 anos, 1 (um) professor-cursista com idade entre 20 e 30 anos e 1 (um) professor-cursista com idade superior a 40 anos, totalizando 5 (cinco) indivíduos. A partir deste perfil de faixa etária, pode-se notar que a procura por cursos como o UEI não está restrita a estudantes mais jovens. A segunda pergunta relacionada ao perfil do respondente foi sobre sua formação inicial. Como resultados, tem-se como participantes, graduados dos cursos de Pedagogia, Letras, Matemática e História, o que também acaba dizendo sobre a pluralidade em contextos formativos como esse.

No que concerne ao motivo que levou os professores-cursistas a se inscreverem para o curso (questão 1), eles escreveram que:

Participante 1: "Tenho interesse pela área. Qdo soube que se tratava de um curso da UFLA, a distância e gratuito, logo procurei conhecer mais sobre o curso. Acabei achando um blog de uma tutora que me explicou tudo. Depois acabei vendo essa tutora no curso, (...). Mas não tive a sorte de ficar com ela."

Participante 2: "Interesse pela área"

Participante 3: "O que me levou foi a necessidade de quanto professora, só estar em sala de aula em um mundo altamente globalizado e digitalizado, o uso da tecnologia em sala de aula deve fazer parte do trabalho docente. Temos de nos adequar a realidade tanto social quanto a dos alunos que são nossa clientela."

Participante 4: "A necessidade de incluir as tecnologias digitais nos conteúdos disciplinares em sala de aula."

Participante 5: "Expectativa de ampliar as possibilidades de articular educação, uso de tecnologias digitais e ensino aprendizagem da disciplina de história no ensino médio."

Em relação à questão 2, que versava sobre a característica do curso UEI, 1 (um) participante escolheu a opção "comportamentalista e tecnicista", enquanto 4 (quatro) a opção "reflexivo e crítico". É importante ressaltar que as definições desses termos não foram apresentadas no questionário. Contudo, foi possível verificar como os respondentes os concebiam a partir da questão seguinte no questionário. Além disso, é válido esclarecer que, tendo em vista o objetivo deste trabalho, desejava-se um posicionamento dos professores-cursistas quanto a sua escolha, por isso, a opção de não inserir alternativas como "Não sei opinar". 
Na questão 3, quando deveriam justificar essas escolhas, os professores-cursistas se mostraram críticos, expressando seu contentamento e/ou insatisfação quanto às experiências vivenciadas. Escreveram a respeito da relação teoria e prática que nem sempre é aplicável em contextos reais, sobre a superficialidade em alguns momentos, sobre a não relação com documentos oficiais como a BNCC e sobre a inadequação de propostas em meio ao contexto contemporâneo. Contudo, escreveram também respostas que descrevem as novidades apresentadas pelo curso, bem como o fato de que, por meio dele, foi possível "conhecer mecanismos e estratégias metodológicas para poder elaborar aulas mais atrativas, dinâmicas de acordo com a realidade de cada sala." Além disso, uma resposta apontou o fato de que ao longo do curso acontecia sempre o estímulo à reflexão sobre "tecnologias digitais em sala de aula e sobre os seus impactos na qualidade do ensino". Ainda como resposta à essa questão, a importância da tutoria é evidenciada, o que também acontece na última questão.

Os relatos dos professores-cursistas (questão 4) também sinalizaram a importância da tutora no processo de construção de conhecimento. Além disso, alguns participantes relataram os momentos de reflexão sobre as tecnologias disponíveis em cada contexto e suas possibilidades. Relataram também a dificuldade de relacionar, em muitos casos, a teoria à prática em seus espaços de atuação. Além disso, um(a) participante se expressou quanto à dificuldade de chegar ao final do curso e quanto à importância de um grupo de WhatsApp com a tutora e com os colegas o(a) apoiando. Ele/Ela pensa que o curso tem potencial, mas está desarticulado com o que há de atual.

Diante dos dados, se considerarmos que professores, ao vivenciarem processos formativos, podem ser vistos como sujeitos capazes de estabelecer mudanças constantes e profundas em seus contextos e na sociedade como um todo [Liberalli, 2010], é possível concluir que, ao que parece, muitos professores-cursistas ainda não se sentem preparados, mesmo após o curso, para serem agentes transformadores no sentido da discussão empreendida por Liberalli. Embora alguns momentos de reflexão e de criticidade tenham sido propiciados, principalmente pelas intervenções da tutora, nem sempre eles parecem fazer sentido para os contextos em que os professores atuam. Além disso, apesar de muitas atividades práticas aconteceram, parece que muitas já não estão em consonância com a contemporaneidade, o que caminha ao encontro da importância de que processos formativos, como o considerando neste artigo, sejam sempre repensados para que sejam, de fato, significativos.

\section{Considerações Finais}

O presente trabalho teve como objetivo identificar e discutir possibilidades de formação crítica de professores na educação a distância, de modo especial, no curso "Uso Educacional da Internet". A partir da pesquisa e das análises empreendidas, foi possível compreender que o curso UEI não se pautou em uma abordagem de formação tradicional apenas, viabilizando, em determinados momentos, a reflexão a respeito da apropriação de novas tecnologias em práticas educativas vivenciadas na escola, o que responde à primeira questão de pesquisa: Quais perspectivas de formação docente estão envolvidas nas atividades realizadas pelos professores no curso?

Uma vez que o curso propiciou vivências reflexivas a partir da teoria e da prática, pode-se afirmar, considerando a segunda questão de pesquisa (há possibilidades, 
considerando o projeto do curso e a forma como as atividades são desenvolvidas, de uma formação crítica-reflexiva, haja vista a sua pertinência em meio às constantes transformações sociais contemporâneas?) que há possibilidades de uma formação crítica, que é, no entanto, concretizada ou não de acordo com a forma como cada um concebe a experiência vivenciada.

A respeito da terceira e última questão de pesquisa (Os professores se engajam em suas vivências formativas ou é notório o anseio pelo crescimento profissional apenas?), foi possível identificar professores que não se engajaram nas discussões e que, possivelmente, buscaram a oportunidade visando um crescimento apenas enquanto profissionais. No entanto, a maioria, considerando aqueles que conseguiram chegar até o final do processo, parece ter aproveitado o curso em um sentido mais holístico, mesmo com as tantas limitações, muitas vezes compartilhadas. Um curso como o UEI já não é mais um lugar de transmissão de conhecimentos, mas de construção de conhecimentos a partir da teoria e da prática, de reflexão, de criticidade.

\section{Referências}

ABED. Censo EAD.BR: relatório analítico da aprendizagem a distância no Brasil 2016 [livro eletrônico]/[organização] ABED - Associação Brasileira de Educação a Distância; [traduzido por Maria Thereza Moss de Abreu]. Curitiba: InterSaberes, 2017.

BRASIL. Base Nacional Comum Curricular. Disponível em: http://basenacionalcomum.mec.gov.br/wp-content/uploads/2018/06/BNCC_EI_EF_110518_ versaofinal_site.pdf. Acesso em: 11 set 2018.

FREIRE, P. \& HORTON, Myles. O caminho se faz caminhando: conversas sobre educação e mudança social. 4 ed. Petrópolis-RJ: Vozes, 2003.

IANNI, O. A sociedade global. Rio de Janeiro: Civilização Brasileira. 1996.

KRAHE, Elizabeth Diefenthaeler. Autonomia, reflexão e formação de professores. ANPED SUL. Jun. 2006.

LIBERALLI, Fernanda Coelho. Formação Crítica de Educadores: Questões Fundamentais. 2 ed. Campinas: Pontes Editores, 2010.

MOITA LOPES, L. P. Oficina de Linguística Aplicada: a natureza social e educacional dos processos de ensino/aprendizagem de língua. Campinas: Mercado de Letras, 1996.

MORAN, José Manuel. Novas Tecnologias e Mediação Pedagógica. 16 ed. Campinas: Papirus, 2009. 173p.

NETO, F. J. E.; CAMPOS, G. R. de. O impacto do neoliberalismo na educação brasileira. In: Anais do XIII EDUCERE, 2017.

PINHEIRO, P. A. A escrita colaborativa por meio do uso de ferramentas digitais: ressignificando a produção textual no contexto escolar. In: Calidoscópio Vol. 9, n. 3, p. 226-239, set/dez 2011.

PRATES, J. C. Gestão estratégica de instituições sociais: o método marxiano como mediação do projeto político. Porto Alegre: PUCRS-PPGSS, maio, 1995.

VAN MANEN, M. Linking ways of knowing with ways of being practical. In: Curriculum Inquiry 6. pp. 1977. 205-228. 